\title{
A Case of Cerebral Cysticercosis in Thailand
}

\author{
Samasuk Thammachantha ${ }^{1, *}$, Ratana Kunnatiranont ${ }^{2}$, Pongwat Polpong ${ }^{3}$ \\ ${ }^{1}$ Department of Pathology, ${ }^{2}$ Department of Neuroradiology, ${ }^{3}$ Department of Neurosurgery, Prasat Neurological Institute, Bangkok 10400, Thailand
}

\begin{abstract}
Cysticercosis and sparganosis are not uncommon parasitic infections in the developing world. Central nervous system infection by both cestodes can present with neurological signs and symptoms, such as seizure and mass effect, including brain hernia. Early detection and accurate diagnosis can prevent a fatal outcome. Histological examinations of brain tissues can confirm the diagnosis of cerebral cysticercosis, which differs from sparganosis by the presence of a cavitated body. We report here a case of cerebral cysticercosis which has the similar clinical and imaging findings as sparganosis.
\end{abstract}

Key words: Cysticercosis, sparganosis, magnetic resonance imaging, neuropathology, epilepsy

\section{INTRODUCTION}

Cysticercosis is an important parasitic infection in the developing countries. It is caused by cestodes, the pork tapeworm, Taenia solium. Humans may be either definitive hosts (adult tapeworms residing in the human intestines) or intermediate hosts (the larval stage residing in the tissues) for T. solium [1].

Humans can become an intermediate host when they either ingest cysticerci (encysted larvae) or consume eggs. Cysticerci are ingested by eating undercooked pork while eggs are usually ingested by eating contaminated foods, including uncooked or inadequately washed raw vegetables or salads [2]. When eggs reach the stomach, gastric enzymes will break down the egg wall and release larvae. The larvae penetrate the intestinal mucosa into the blood circulation and form cysticerci which can be found in any part of the body, especially central nervous system (neurocysticercosis). There are 2 main forms of neurocysticercosis [3]. One is "isolated cyst" (cysticercus cellulosae), and the other is "racemose cyst (cysticercus racemosus) [4].

We report a case of cerebral cysticercosis in Bangkok, Thailand of which imaging studies showed an atypical convoluted lesion, similar to sparganosis, another kind of cestode infection in the brain.

- Received 3 August 2016, revised 28 September 2016, accepted 1 October 2016.

*Corresponding other (shisuku175@yahoo.com)

(c) 2016. Korean Society for Parasitology and Tropical Medicine

This is an Open Access article distributed under the terms of the Creative Commons Attribution Non-Commercial License (http://creativecommons.org/licenses/by-nc/4.0) which permits unrestricted non-commercial use, distribution, and reproduction in any medium, provided the original work is properly cited.

\section{CASE RECORD}

A 30-year old Thai female presented to the outpatient clinic with generalized tonic-clonic seizure 1 week ago. The duration of the seizure was less than $1 \mathrm{~min}$. The patient passed out for 1 $\mathrm{hr}$, and gained consciousness without memory deficit. There was no history of fever, vomiting, headache, or visual disturbances. No history of previous accident, drug allergy, or cancer was present. Her physical examination was normal. The brain MRI revealed a conglomeration of several small ring enhancing lesions of $1.9 \times 1.4 \times 1.6 \mathrm{~cm}$ in size, at the cortical posterior left middle frontal gyrus. Neither midline shift nor hydrocephalus was seen (Fig. 1). A chest $\mathrm{x}$-ray showed an unremarkable finding. No abnormal calcification was detected by plain radiograph of the femur. Routine blood examinations showed an absence of eosinophilia, and stool examinations showed no parasites.

A left frontal craniotomy was done. A greyish white cyst of about $1 \times 2 \times 1 \mathrm{~cm}$ in size filled with clear fluid and small white nodule was removed. Multiple sections studied revealed necrotic material with neutrophils, mononuclear cells, some eosinophils, surround by granulation tissues (Fig. 2A). Nearby the necrotic material, a cyst with cavitory larva of T. solium was found. There were numerous branching and duct-like invaginations (Fig. 2B). Staining with PAS (periodic acid-Schiff) revealed microvilli (Fig. 2C), while Von Kossa staining revealed calcified corpuscles (Fig. 2D).

The patient was treated with albendazole for 3 weeks and was doing well at 1 month follow up. Her family denied any history of cysticercosis. 

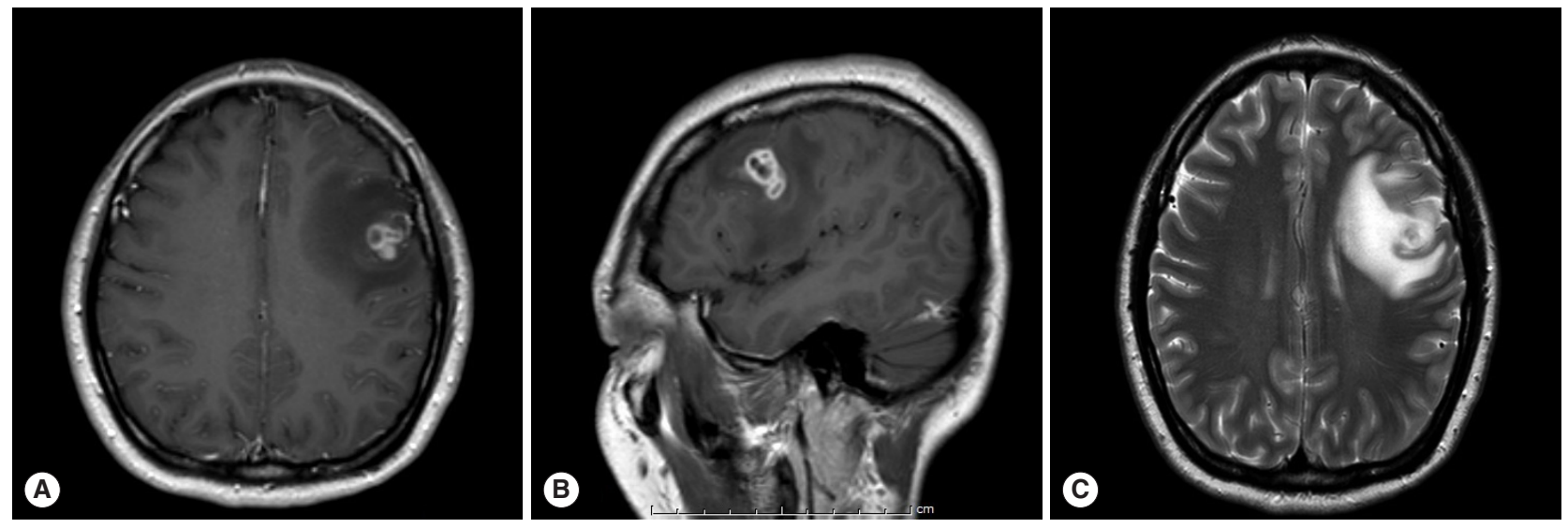

Fig. 1. MRI findings of the patient. (A) Horizontal section of T1 weighted MRI of lesion with ring enhancement. (B) Sagittal section of T1W MRI. (C) T2-weighted MRI with perilesional edema.
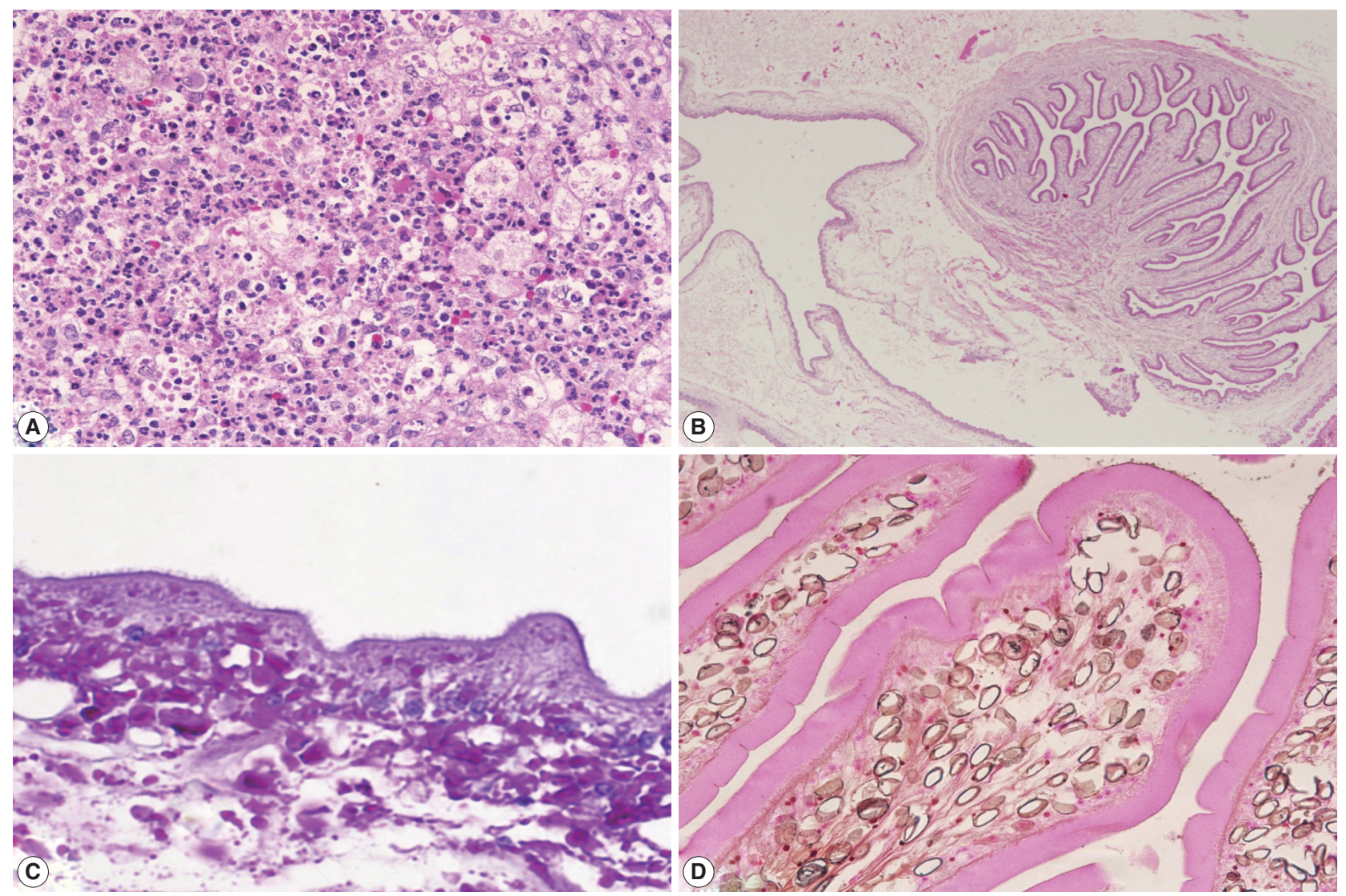

Fig. 2. Histopathological findings of the patient. (A) Necrotic areas with inflammation. (B) The parasite with branching internal structures. (C) Microvilli at outer membrane of the cyst. (D) Calcified corpuscles inside the parasite.

\section{DISCUSSION}

Parasitic infections of the central nervous system can share similar clinical presentations, depending on the location, size, and number of lesions, and the inflammatory responses evoked by the parasites [2,3]. Regarding cerebral infections in developing countries, the possible diagnosis of the patient with confluent ring enhancing lesion by MRI can be due to cysticercosis, sparganosis, and even tuberculoma [4].

Regarding the imaging studies, Kim et al. [5] described the 
Table 1. Various stages of neurocysticercosis

\begin{tabular}{|c|c|}
\hline Stage & MRI findings \\
\hline 1. Non cystic & Undetectable \\
\hline 2. Vesicular & $\begin{array}{l}\text { Cyst signal intensity similar to that of CSF on T1- } \\
\text { and T2-weighted images; cyst wall is well de- } \\
\text { fined and thin, with little or no enhancement on } \\
\text { gadolinium-enhanced images; scolex can be } \\
\text { demonstrated in up to a } 50 \% \text { of the cases }\end{array}$ \\
\hline 3. Colloidal vesicular & $\begin{array}{l}\text { Cyst contents hyperintense on T1- and T2- } \\
\text { weighted images (proteinaceous fluid), cyst wall } \\
\text { is thick and hypointense, pericystic edema, peri- } \\
\text { cystic enhancement on gadolinium-enhanced } \\
\text { images }\end{array}$ \\
\hline 4. Granular nodular & $\begin{array}{l}\text { Similar to colloidal vesicular stage but with more } \\
\text { edema, thicker ring enhancement }\end{array}$ \\
\hline 5. Calcified nodular & $\begin{array}{l}\text { Hypointense nodules, no edema, no enhance- } \\
\text { ment }\end{array}$ \\
\hline
\end{tabular}

features of sparganosis by MRI as widespread white matter degeneration and cortical atrophy, and mixed-signal lesions with irregular dense enhancement of central foci. Viable cysticerci can be diagnosed on MRI as cystic lesions which appear hypointense on $\mathrm{T} 1$ and hyperintense on $\mathrm{T} 2$ with an eccentric nodule. When the cyst degenerates, fluid leaks out and creates inflammation which is seen as peripheral enhancement on MRI and CT. Also, variable degrees of edema may be seen in the surrounding tissues $[6,7]$.

Dubey et al. [8] claimed that soft tissue cysticercosis can be seen as elongated calcification along the muscle fibers on plain radiographs and CT scan, once the larvae become a final calcified stage, but not the early stage of live cysticerci. So, a combination of MRI and ultrasonography can be confidently used to diagnose non-invasive cysticercosis in soft tissues [8].

The definite diagnosis of cysticerci can be made only by tissue biopsy. Spargana differ from cysticerci by the absence of bladder walls and armed scolex and the presence of solid noncavitated body [9]. However, in our case we could not find the scolex by histological studies. Teitelbaum et al. [10] claimed that the scolex in cysticercosis is found in nearly $50 \%$ of cases. The reason why we cannot find the scolex is related to "stages of the disease". According to the stage of the cyst, our case was compatible with "colloidal vesicular stage", in which larvae begin to degenerate and scolex disintegrates, with surrounded striking inflammatory responses as shown in Table $1[11,12]$.

Recently, there is a PCR technique which can help molecular genetic confirmation [13]. Unfortunately, we lack molecular facilities in our center. We hope that we will have a chance to investigate more in the future.

\section{CONFLICT OF INTEREST}

We do not have any conflict of interest related to this work.

\section{REFERENCES}

1. Garcia HH, Del Brutto OH. Neurocysticercosis: updated concepts about an old disease. Lancet Neurol 2005; 4: 653-661.

2. Garcia HH, Del Brutto OH. Taenia solium cysticercosis. Infect Dis Clin North Am 2000; 14: 97-119.

3. Agapejev S. Neurocysticercosis: the enigmatic disease. Cent Nerv Syst Agents Med Chem 2011; 11: 261-284.

4. Prasad KN, Prasad A, Verma A, Singh AK. Human cysticercosis and Indian scenario: a review. J Biosci 2008; 33: 571-582.

5. Kim H, Kim SL, Cho SY. Serological diagnosis of human sparganosis by means of micro-ELISA. Korean J Parasitol 1984; 22: 222-228.

6. Sirikulchayanonta V, Jaovisidha S. An intramuscular cysticercosis, a case report with correlation of magnetic resonance imaging and histopathology. J Med Assoc Thai 2007; 90: 1248-1252.

7. Jankharia BG, Chavan GB, Krishnan P, Jankharia B. MRI and ultrasound in solitary muscular and soft tissue cysticercosis. Skeletal Radiol 2005; 34: 722-726.

8. Dubey P, Chodankar R, Chawla L, Bhat T, Rani V. Isolated forearm swelling-a rare presentation of soft tissue cysticercosis. Am J Med Case Reports 2014; 2: 243-246.

9. Lescano AG, Zunt J. Other cestodes: sparganosis, coenurosis and Taenia crassiceps cysticercosis. Handb Clin Neurol 2013; 114: 335345.

10. Teitelbaum GP, Otto RJ, Lin M, Watanabe AT, Stull MA, Manz HJ Bradley WG Jr. MR imaging of neurocysticercosis. AJR Am J Roentgenol 1989; 153: 857-866.

11. Kimura-Hayama ET, Higuera JA, Corona-Cedillo R, ChávezMacías L, Perochena A, Quiroz-Rojas LY, Rodríguez-Carbajal J, Criales JL. Neurocysticercosis: radiologic-pathologic correlation. RadioGraphics 2010; 30: 1705-1719.

12. Costantino SA, Capiel CA, Rossini SA, Landi M, Bouzas CA. Diagnostic imaging in neurocysticercosis. Rev Arg Diag Por Imágenes 2012; 1: 24-30.

13. Jeon HK, Yong TS, Sohn WM, Chai JY, Min DY, Rim HJ, Insisiengmay B, Eom KS. Human neurocysticercosis case and an endemic focus of Taenia solium in Lao PDR. Korean J Parasitol 2013; 51: 599-602. 
